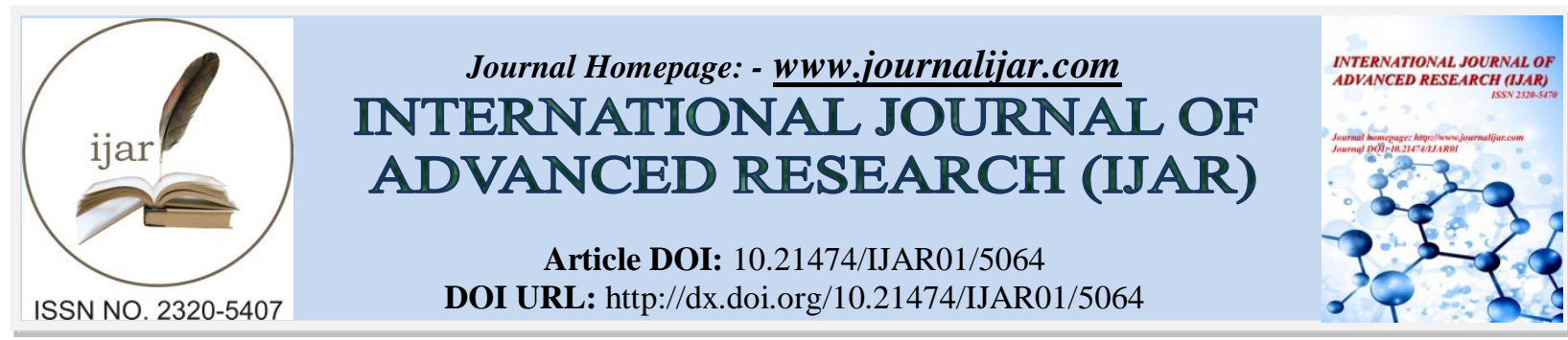

RESEARCH ARTICLE

\title{
RED CELL ALLOIMMUNIZATION IN REPEATEDLY TRANSFUSED CHRONIC RENAL FAILURE PATIENTS IN JAIPUR.
}

Mr. Ziad Amran ${ }^{1}$, Prof. Dr. Manju Mhera ${ }^{2}$ and Prof. Dr. Pankaj Agarwal ${ }^{3}$.

1. Ph.d Research Scholar, Medical Lab Technology-Pathology, NIMS Medical College and Hospital, JaipurIndia, Pin Code 302002.

2. (Ph.d Guide), Pathology, NIMS Medical College and Hospital, Jaipur.

3. (Ph.d Co-Guide), Microbiology, Blood bank, SDM Hospital, Jaipur.

\section{Manuscript Info}

(..........................

Manuscript History

Received: 04 June 2017

Final Accepted: 06 July 2017

Published: August 2017

Key words:-

Alloimmunization; Chronic renal failure (CRF); Anemia; Multiple Transfusions.

\section{Abstract}

Background: Alloantibodies formation against red blood cell (RBC) antigens is the most common complication of transfusion therapy especially in multiple transfusions. Chronic renal failure (CRF) patients need regular blood transfusion support to treat anemia additional to recombinant human erythropoietin (RHuEpo) treatment. Aim: To determine the frequency of red cell alloantibodies in (CRF) patients and to identify the common alloantibodies. Materials and Methods: A total of 39 samples were collected from chronic renal failure patients from Nims and SDM Hospital in Jaipur-India. Laboratory investigations have done by (BioVue cassettes based on Column Agglutination Technology) in blood bank - SDM Hospital include: ABO, Rh blood grouping and $\mathrm{Du}$ testing, Indirect Comp's Test (ICT), Antibody screening by Ortho Surgiscreen ( 3 cell panel in Ortho BioVue AHG polyspecific cassettes), antibody identification using 11 cells panel by Ortho Resolve Panel. Results: Out of 39 patients of CRF $24(61.5 \%)$ were males and 15 $(38.5 \%)$ were females. The prevalence of alloantibodies among CRF patients was $18 \%$ and the most common alloantibodies were anti-M (25\%) which is detected in 2 patients and (Anti-C, Anti-c, Anti-E, Anti$\mathrm{N}$, Anti-Fy $^{\mathrm{a}}$, Anti-Fy ${ }^{\mathrm{b}}$ ) were at the same rate $(12 \%)$ where all antibodies were IgG class. The most common blood group among our patients was $\mathrm{B}$ positive which is detected in 5 patients $(71 \%)$. Conclusion: Several factors might have contributed to the high a lloimmunization prevalence observed in this study, heterogeneity of the population living in Jaipur, lack of better-matched donors for those patients, no use of leukodepleted blood. Antibodies screening of patients and antigens detection on RBCs of donor especially ( $\mathrm{Rh}$ and Kell antigens) have to do to avoid development new alloantibodies.

Copy Right, IJAR, 2017,. All rights reserved.

\section{Introduction:-}

Red blood cell alloimmunization is a common complication among chronic renal failure (CRF) patients who need regular blood transfusion. ${ }^{1,2}$ Chronic red cell transfusions can cause unwanted complications called transfusion reactions in a patient. Development of alloantibodies to red cell antigens is an important immune mediated delayed 
hemolytic transfusion reaction. ${ }^{3}$ Immune response due to genetic difference between the blood donor and the recipient induces the formation of alloantibody. The other factors that influence alloantibody formation are the recipient's immune status as well as the dose, single or multiple transfusions, age, route of administration and the immunogenicity of the antigen. ${ }^{4}$

The National Kidney Foundation (NKF) defines chronic kidney disease as kidney damage or glomerular filtration rate (GFR) of less than $60 \mathrm{ml}$ per minute per $1.73 \mathrm{~m} 2$ (body surface area) for three months or more. ${ }^{5}$ Using World Health Organization (WHO) definitions of anemia, $87 \%$ of patients with GFR below $25 \mathrm{ml} / \mathrm{min}$, but not yet on dialysis have anemia. However in the current era, $85 \%$ of patients are commencing dialysis with Hb levels below $10.0 \mathrm{~g} / \mathrm{dl}^{5}$ Anemia also defined, according to (WHO) criteria, to be that level of hemoglobin below age- and genderdetermined normal ranges. Thus, for males and non-menstruating females, anemia is defined as $\mathrm{Hb}<13.5 \mathrm{~g} / \mathrm{dl}$, while in premenopausal women, anemia is defined as a $\mathrm{Hb}<11.5 \mathrm{~g} / \mathrm{dl}$. Using these definitions, a large proportion of patients with chronic kidney disease have anemia, and most dialysis patients remain anemic throughout the course of their dialysis life. The etiology of the anemia was eventually determined to be primarily due to the reduction of erythropoietin production and activity. ${ }^{5,6}$ As well anemia is a severe complication of chronic kidney disease (CKD) that is common in more than $80 \%$ of patients with impaired renal function. ${ }^{7}$

Erythropoietin (EPO) and iron therapy have been successful in increasing Hb levels in dialysis patients, decreasing the need for RBC transfusions, and improving a patient's general well-being. ${ }^{8}$ EPO, which is produced by the liver in the fetus and by the kidney in the adult, is the primary stimulus of red blood cell formation. In contrast, in patients with chronic renal failure, production of EPO is impaired, and this EPO deficiency is the primary cause of their anemia. $^{9}$

Recombinant human erythropoietin (RHuEpo) has revolutionized the treatment of patients with anemia of chronic renal failure. But the presence of other medical problems may affect the use of erythropoietin, causing poor responses including aluminum poisoning, blood clots or other problems with the blood. ${ }^{2,5}$ Alloantibodies sensitization results in difficulty obtaining compatible blood, transfusion reactions, hemolysis and occasionally lifethreatening events. ${ }^{2,4}$

Several studies have demonstrated the incidence of alloimmunization among thalassemia and sickle cell disease, However, little estimated among chronic renal disease patients, as study that reported RBC alloimmunization rate of $9.8 \%$ in chronic renal failure patients undergoing haemodialysis, ${ }^{2}$ and other study have reported low rate $6.1 \%$ of antibody formation in the same group of patients, ${ }^{10}$ as well there study showed incidence was $13.1 \%{ }^{4}$

This study was conducted to determine the frequency and specificity of the red cell alloantibody detected in chronic renal failure patients in Jaipur, in order to provide appropriate recommendations for the care of these patients.

\section{Material and methods:-}

A total of 39 samples were collected from chronic renal failure patients from Nims and SDM Hospital. This study was approved by ethical committee-Nims University, and an informed consent was obtained from the patients after explaining the purpose of the study. Two blood samples with volume of $4 \mathrm{ml}$ were collected from each patient for standard tube EDTA and plan. Laboratory investigations were done to all the studied patients including: ABO, Rh blood grouping and Du testing have done by (BioVue cassettes based on Column Agglutination Technology), Indirect Comp's Test (ICT) have done for patients' blood samples to detect the irregular antibodies (BioVue cassettes), antibodies screening by Ortho Surgiscreen (3 cell panel in Ortho BioVue AHG polyspecific cassettes), finally, specimens found positive for irregular antibody were subjected to alloantibody and autoantibody identification using 11 cells panel by Ortho Resolve Panel A (11 cell panel in BioVue AHG polyspecific cassettes) based on Column Agglutination Technology. A cross sectional study was done in the blood bank - SDM Hospital during the period from May 2016 to July 2017.

\section{Results:-}

A total of 39 patients diagnosed chronic renal failure and received at least two units of red blood cell transfusion were screened for the presence of red blood cell alloantibodies. Out of 39 patients of chronic renal failure 24 $(61.5 \%)$ were males and $15(38.5 \%)$ were females. The age range was from 18 year to 74 years with the mean age of 42 year. Seven patients $(18 \%)$ of the total number of patients (39) were found to have alloantibodies to RBCs 
(Figure 1), of these patients, 6 patients (85\%) developed single antibody while one (15\%) patients developed dual alloantibody in their sera. Alloantibodies development in patients at $\geq 35$ years $(n=4 / 57 \%)$ more than $\leq 35$ years $(\mathrm{n}=3 / 43 \%)$. Out of 7 alloantibodies, the most alloantibody frequent combination was anti-M (25\%) which is detected in 2 patients and (Anti-C, Anti-c, Anti-E, Anti-N, Anti-Fy ${ }^{\mathrm{a}}$, Anti-Fy ${ }^{\mathrm{b}}$ ) were at the same rate (12\%) where all antibodies were IgG class. The most common blood group among our patients was B positive which is detected in 5 patients $(71 \%)$.

Figure 1:- Frequency of red blood cell alloantibodies:

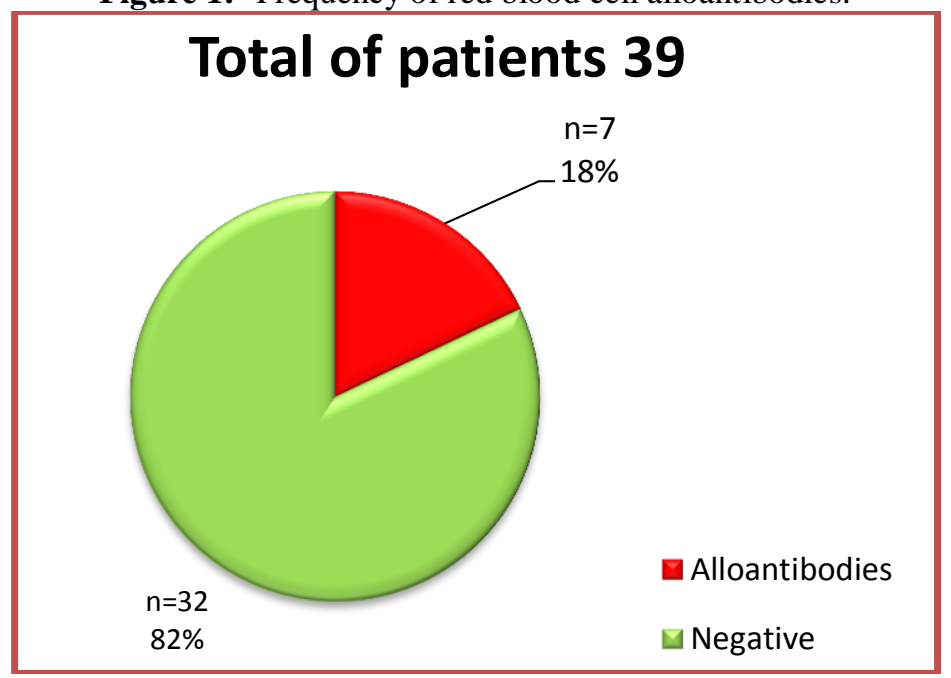

( $\mathrm{n}=$ number of patients)

Table 1:- Details of immunized patients:

\begin{tabular}{|l|l|l|l|l|}
\hline SN. & Gender & Age & Antibody & ABO \& Rh Group \\
\hline 1 & F & 46 & Anti-M & B + \\
\hline 2 & M & 25 & Anti-M & A+ \\
\hline 3 & F & 25 & Anti-C & A+ \\
\hline 4 & F & 40 & Anti-c & B+ \\
\hline 5 & M & 74 & Anti-N & B+ \\
\hline 6 & F & 41 & Anti-Fy & B + \\
\hline 7 & M & 35 & $\begin{array}{l}\text { Anti-E } \\
+ \text { Anti-Fy }^{b}\end{array}$ & B+ \\
\hline
\end{tabular}

Figure2:- Frequency of different alloantibodies:

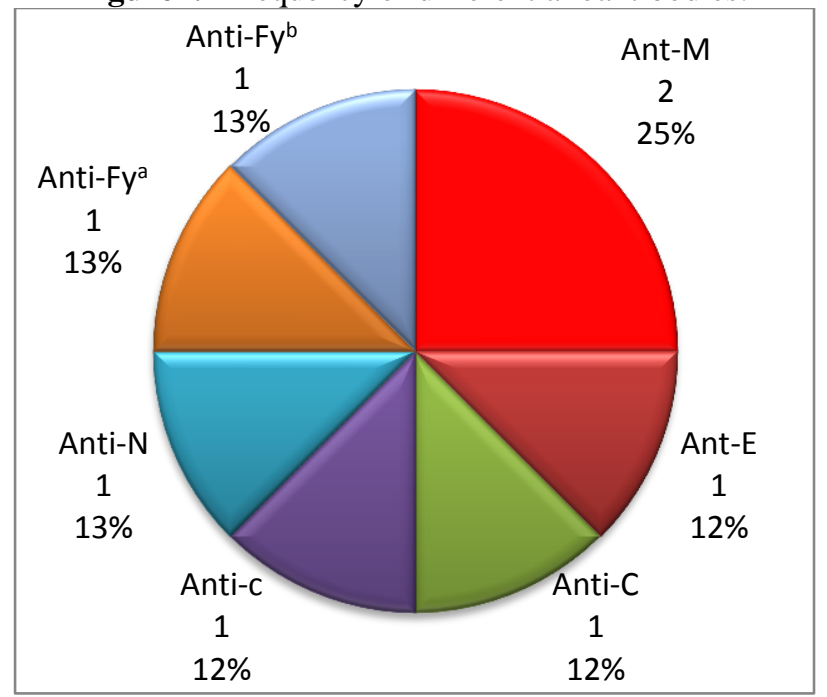




\section{Discussion:-}

Only a few studies in chronic renal failure, mostly in transfused thalassemia patients, Sickle cell disease, have investigated the frequency and causes of alloimmunization and autoimmunization.

In the present study we estimated these elements and defined the common alloantibodies among chronic renal failure, Rajasthani patients, which have not been previously described.

RBC alloimmunization results from disparity of antigens between donor and recipient. Recipient's immune status immunogenicity of the antigen and dose of the antigen are the factors which play a significant role in alloimmunization. Thereby, antibodies arise in the chronic renal failure patients after exposure to multiple of red blood cell transfusions. ${ }^{4}$

We observed of alloimmunization prevalence was $18 \%$ detected in 7 out of 39 CRF patients, this finding is higher than the frequency of previous studies have done in Sudan country that they reported of prevalence $13.1 \%{ }^{4}$, Similarly study by Domen and Ramirez showed the rate $6.1 \%^{10}$ and frequency of $9.9 \%$ reported by Shukla ${ }^{2}$ in CRF patients undergoing dialysis while study by Patel et al. ${ }^{11}$ had been shown that the alloimmunization rate $8.2 \%$ in CRF patients.

The high prevalence in our study may be because little number of patients, only 39 . In spite of, there are many chronic renal failure patients in the Jaipur but lack of cooperation from most hospitals and did not allow us to collect samples from all centers.

The differences in the alloinummization rate were attributed to: Heterogeneity among the Rajasthani population, in the most hospitals the pre-transfusion test blood were matched only for $\mathrm{ABO}$ and $\mathrm{Rh}(\mathrm{D})$ antigens, high cost of antibody screening and identification tests and sensitivity of the test method . It has been reported that if blood were matched only for $\mathrm{ABO}$ and $\mathrm{Rh}$ groups, a high rate of alloimmunization would be expected especially multiple blood transfusions. ${ }^{12}$ Some investigators have suggested the use of extended red blood cell phenotyping for antigen other than $\mathrm{ABO}$ and $\mathrm{Rh}(\mathrm{D})$ for some multi-transfused patient in order to reduce the risk of alloimmunization. ${ }^{2}$ Based in our data, out of 7 alloantibodies development, the most alloantibody frequent combination was belong to Rh blood system (37.5\%) which is detected in 3 patients (Anti-C 12.5\%, Anti-c 12.5\%, Anti-E 12.5\%) similar to MNs $(37.5 \%)$ in 3 patients also (Anti-M 25\%, Anti-N 12.5\%) while Duffy (25\%) which is detected in 2 patients (Anti-Fy ${ }^{\mathrm{a}}$ $12.5 \%$, Anti-Fy $\left.{ }^{\mathrm{b}} 12.5 \%\right)$ were at the same rate (12\%).

\section{Conclusion:-}

Recombinant human erythropoietin (RHuEpo) treat instead of RBC transfusion, extended phenotype matched, leucodepleted red cell transfusion is recommended in prevention of alloimmunization. Antigen detection on RBCs of donor especially ( $\mathrm{Rh}$ and Kell antigen) has to do to avoid development alloantibodies. Suggestion for future study, have to include all CRF patients in jaipur.

\section{References:-}

1. Walker RH, Lin DT, Hatrick MB (1989). Alloimmunizaton following blood transfusion. Arch Pathol Lab Med 113:254-261.

2. Shukla JS, Chaudhary RK (1999). Red cell alloimmunization in multitransfused chronic renal failure patients undergoing hemodialysis. Indian J Pathol Microbiol 42:299-302.

3. Rashmi Sood et al. Detection of alloimmunization to ensure safer transfusion practice. Asian Journal of Transfusion Science - Vol 7, Issue 2, July - December 2013.

4. Hythum Abdullah M. Babiker et al. Frequency of Alloantibodies among Chronic Renal Failure Patients in Red Sea State. Indian Journal of Hematology and Blood Transfusion September 2014, Volume 30, Issue 3, pp 187190.

5. Isam Hamo Mahmood et al. Human recombinant erythropoietin in the treatment of anemia of patients with chronic renal failure. The medical journal of basrah university, MJBU, vol 27, No.1, 2009.

6. Edmund G. et al. Anemia in Patients with Chronic Renal Failure and in Patients undergoing Chronic Hemodialysis. http://msl1.mit.edu/ESD10/kidneys/HndbkHTML/ch19.htm.

7. Melnikova I (2006). Anemia therapies. Nat Rev Drug Discov 5:627-628. 
8. Yvette C. Tanhehco and Jeffrey S. Berns. Red Blood Cell Transfusion Risks in Patients with End-Stage Renal Disease. DOI: 10.1111/j.1525-139X.2012.01089.x.

9. Ratcliffe PJ (1993). Molecular biology of erythropoietin. Kidney Int 44:887-904.

10. Doman RE, Ramire ZG (1988). Red cell alloimmunization in chronic renal failure patients undergoing hemodialysis. Nephron 48:284-285.

11. Patel J, Shukla R, Gupte S (2009). Red cell alloimmunization in multitransfused patients and multiparous women. Ind J Hematol Blood Transfus 25(2):49-52.

12. Spanos T, Karageorga M, Ladis V, Peristeri J, Hatziliami A, Kattamis C (1990). Red cell alloantibodies in patients with thalassemia. Vox Sang 58:50-55. 